Article

\title{
Mapping Development Pattern in Beijing-Tianjin-Hebei Urban Agglomeration Using DMSP/OLS Nighttime Light Data
}

\author{
Yi'na Hu ${ }^{1}$, Jian Peng ${ }^{1, *}$, Yanxu Liu ${ }^{1}$, Yueyue $\mathrm{Du}^{1}{ }^{1}$, Huilei $\mathrm{Li}^{1}$ and Jiansheng $\mathrm{Wu}^{2}$ \\ 1 Laboratory for Earth Surface Processes, Ministry of Education, College of Urban and Environmental \\ Sciences, Peking University, Beijing 100871, China; huyina@pku.edu.cn (Y.H.); liuyanxu@pku.edu.cn (Y.L.); \\ duyueyue91@pku.edu.cn (Y.D.); lihuilei@pku.edu.cn (H.L.) \\ 2 Key Laboratory for Environmental and Urban Sciences, School of Urban Planning and Design, Shenzhen \\ Graduate School, Peking University, Shenzhen 518055, China; wujs@pkusz.edu.cn \\ * Correspondence: jianpeng@urban.pku.edu.cn; Tel.: +86-10-6275-0926
}

Received: 29 May 2017; Accepted: 17 July 2017; Published: 23 July 2017

\begin{abstract}
Spatial inequality of urban development may cause problems like inequality of living conditions and the lack of sustainability, drawing increasing academic interests and societal concerns. Previous studies based on statistical data can hardly reveal the interior mechanism of spatial inequality due to the limitation of statistical units, while the application of remote sensing data, such as nighttime light (NTL) data, provides an effective solution. In this study, based on the DMSP/OLS NTL data, the urbanization type of all towns in the Beijing-Tianjin-Hebei urban agglomeration was analyzed from the aspects of development level and speed. Meanwhile, spatial cluster analysis of development level by local Moran's I was used to explore spatial inequality, and the trend was discussed by comparing the development characteristics on both sides of the transition line of different development levels (inequality boundary). The results showed that the development level of the whole region increased dramatically as the mean DN value increased by $65.99 \%$, and $83.72 \%$ of the towns showed a positive development during 2000-2012. The spatial distribution of urbanization types showed that Beijing and Tianjin were at a high urbanization level with rapid speed of development, with the southern region having a medium development level and the northwestern region lagging behind. The spatial cluster analysis also revealed a gradually intensifying trend of inequality as the number of towns with balanced development reduced by 319 during 2000-2012, while the towns in the high-high areas increased by 99 and those in the low-low areas increased by 229. Moreover, the development speed inside the inequality boundary was obviously higher than that outside, indicating an increasingly serious situation for spatial inequality of urban development in the whole region.
\end{abstract}

Keywords: spatial inequality; urbanization type; DMSP/OLS; Beijing-Tianjin-Hebei urban agglomeration

\section{Introduction}

Urbanization is one of the main trends in the world nowadays [1,2]. By 2008, urban areas have been housing over $50 \%$ of the global population, contributing over $80 \%$ of global economic growth [3,4]. With the rapid pace of urbanization globally, urban areas are demonstrating a trend towards clustered development, as urban population grow sharply, built-up areas expand rapidly, and cities thus become more closely interlinked [5]. Urban aggregation has gradually become the key area for implementing development strategies in regional urbanization [6]. Studies on urban agglomeration have also been a heated topic among scholars in both natural and social sciences $[7,8]$. In the early period of urbanization, like China in the 1980s, the pace of development of cities inside an urban 
agglomeration was relatively slow and in a balanced pattern. With the acceleration of the urbanization process, some individual cities would attract more resources to achieve rapid development, while their surrounding cities remain less developed. In the course of this development, spatial inequality of urban development emerged. Spatial inequality refers to the disparities among spatial units of a region $[9,10]$. It matters in two aspects-on one hand, it causes problems concerning equity since fairness cannot be ensured in the development process, thus inducing further problems like inequality of welfare and lack of sustainability [11]; on the other hand, the developed spatial units usually grow continuously while the backward ones face the threat of stagnation. Should these occur, a hardly reversible trend of poverty might result, leading to an unsustainable form of development. The primary cause of spatial inequality of urban development is the difference in development characteristics of different regions inside an urban agglomeration. Therefore, it is of great significance to study the internal development patterns within the cities in an urban agglomeration so as to contribute to the alleviation of spatial inequality and promote the process of regional integration.

Conventionally, studies on urban agglomeration were mainly based on statistical analysis of social-economic indicators, such as population and gross domestic product (GDP) [12-14]. Concepts like megalopolis, metropolitan area and metropolitan belt were all defined by population density in these studies at the first place. The theme of these researches were also confined to the discussion of the concept [14,15] and spatial range identification [16]. However, limited by the demarcation of administrative units in the collection of socio-economic data, it is difficult to accurately identify the boundary of an urban agglomeration, hindering the exploration of cities' internal spatial pattern. In the last few decades, remote sensing has been recognized as a major source of consistent and continuous data, widely adopted in the study of urbanization [17-19]. Among various remote sensing data, the defense meteorological satellite program/operational linescan system (DMSP/OLS) nighttime light (NTL) data provides one of the most important indicators in urbanization studies because of its temporal coverage at the global level since 1992 [20-23]. Therefore, more and more scholars have begun to use NTL data in the study of urban agglomeration [24]. For example, Lo [7] visually identified 10 most notable urban spatial clusters in China, proving the potential of NTL data to detect urban spatial clusters besides extracting urban built-up areas. Yu et al. [8] proposed a new method based on minimum spanning tree and object-oriented method, applying it to the extraction of urban agglomerations in China. Yi et al. [25] used NTL data to study the urbanization in northeastern China from 1992 to 2010, analyzing the urbanization process of 34 prefecture-level cities by a unit circle model. Generally speaking, the focus of studies has gradually turned from spatial range identification to the detection of spatial pattern characteristics inside urban agglomerations, and the spatial inequality between different cities inside urban agglomerations has captured more and more attention.

The Beijing-Tianjin-Hebei urban agglomeration is the largest and most developed urbanized region in northern China. Since the 1990s, the economic growth of the Beijing-Tianjin-Hebei urban agglomeration has progressed significantly. However, regional inequality of social-economic development has been increasing simultaneously [26,27]. Specifically, Beijing and Tianjin have been enjoying at a continuously high development level despite the slow pace of development of surrounding counties, forming a poverty belt around the two major cities. The increasingly severe spatial inequality has plagued the sustainable development of the Beijing-Tianjin-Hebei urban agglomeration [28]. At present, China is vigorously carrying out programs to support the construction of small towns, and towns have become the key focus of urban development in China. In this study, the development characteristics of towns in the provincial-level Beijing City, Tianjin City and Hebei Province were analyzed from the perspectives of development level and development speed based on NTL data. For this purpose, internal towns within the provincial-level administrative units were divided into different urbanization types as well. The spatial inequality of urban development was analyzed using the Local Moran' I. In addition, we explored the evolution trend of such spatial inequality by comparing the development characteristics inside and outside the inequality boundary. In sum, this study aimed to address two main questions: (1) what was the development pattern in 
Beijing-Tianjin-Hebei urban agglomeration during 2000-2012? And (2) what was future trend of the spatial inequality?

\section{Materials and Methods}

\subsection{Study Area}

The Beijing-Tianjin-Hebei urban agglomeration is located in the heart of China's Bohai Rim (Figure 1). It mainly comprises 13 cities: Beijing, Tianjin, Shijiazhuang, Tangshan, Baoding, Qinhuangdao, Langfang, Cangzhou, Chengde, Zhangjiakou, Hengshui, Xingtai, and Handan, with an area of about 200 thousand $\mathrm{km}^{2}$. As the critical political and cultural center of China, the Beijing-Tianjin-Hebei region is the largest and best-developed urban agglomeration in northern China. However, compared to the Yangtze River Delta urban agglomeration and the Pearl River Delta urban agglomeration, the development of Beijing-Tianjin-Hebei urban agglomeration is relatively slow and unequal. By 2012, the proportion of urban population in Beijing and Tianjin was as high as $86.20 \%$ and $81.55 \%$ respectively, while the proportion in Hebei Province was only $46.8 \%$, even below the national average. Meanwhile, the gaps in government revenue, per-capita GDP and other indicators between Beijing, Tianjin and Hebei Province have widened gradually, making it difficult for Hebei Province to absorb the industries transferred from Beijing and Tianjin or receive economic radiation from the major cities. Hebei Province is in a weak position in both competition and cooperation with Beijing and Tianjin, and such spatial inequality of regional development has not been improved effectively up till now.

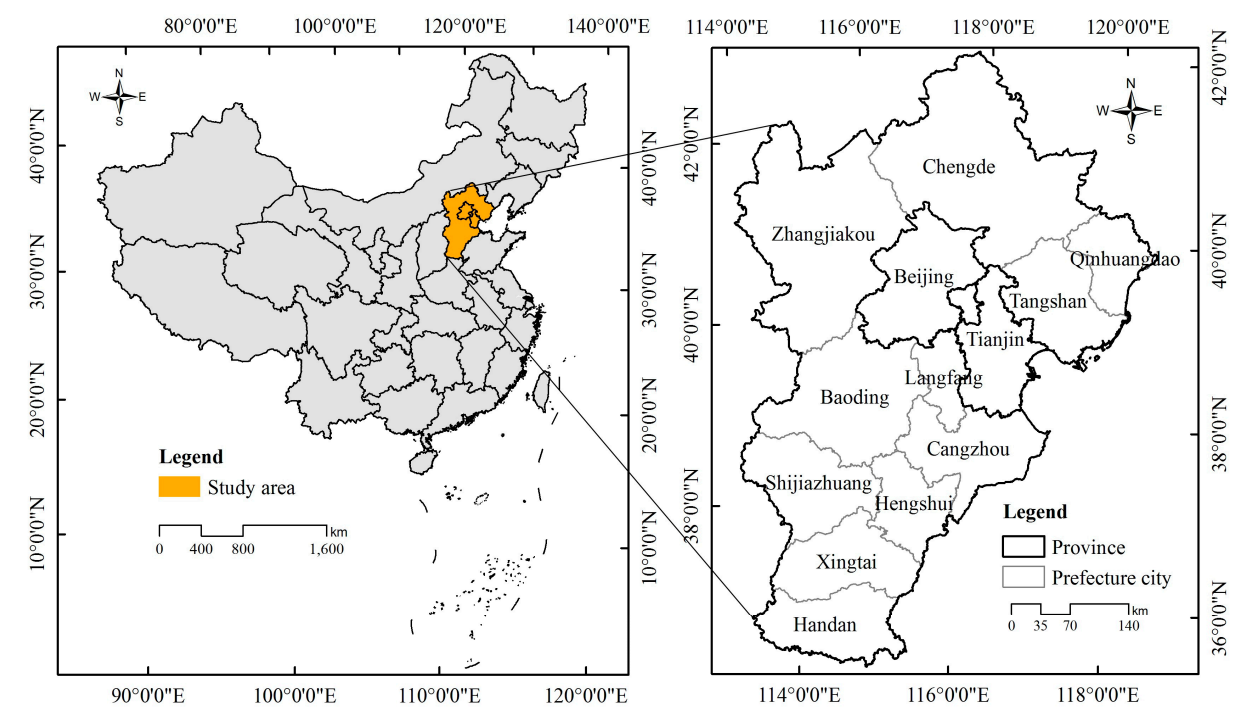

Figure 1. Location of study area.

\subsection{Data sources}

The defense radio systems program was launched in 1976. Its operational linescan system sensors operate at night to detect low-intensity lights from city lights, small-scale settlements, and traffic, making the lights distinct from the dark countryside background [29,30]. The DMSP/OLS nighttime light data in this study was obtained from The National Oceanic and Atmospheric Administration's National Geophysical Data Center (NOAA/NGDC) website with $1 \mathrm{~km}$ image resolution [31]. As the time span of night light data series was long, a total of six satellites were used in the collection process: F10 (1999-1994), F12 (1994-1999), F14 (1997-2003), F15 (2000-2007), F16 (2004-2009), and F18 (2010-2012). There existed some deviations in compatibility and stability of NTL data due to orbital parameters, technical equipment differences and atmospheric refraction between satellites [32]. It resulted in obvious abnormal fluctuations in $\mathrm{DN}$ value in the images obtained by the same satellite 
in different years and by different satellites in the same year. A series of data preprocessing was therefore required.

In this study, we used the systematic correction method proposed by Liu et al. to correct the images of different years and different satellites so as to promote the continuity and comparability of the NTL data [33]. This involved three main steps: inter-calibration, intra-annual composition and inter-annual series correction. After data processing, the intra-annual unstable lit pixels were removed and inter-annual discrepancies of $\mathrm{DN}$ values were reduced to the minimum. These rendered the DN values among different years and from different satellites comparable [34].

\subsection{Methods}

In this study, the development pattern of the Beijing-Tianjin-Hebei urban agglomeration was explored from the spatial pattern of urbanization types and spatial cluster analysis. Firstly, the study area was categorized into different urban development types based on the development level in 2012 and the development speed during 2000-2012, namely (i) highly urbanized zone with high development speed (HUZHDS); (ii) highly urbanized zone with low development speed (HUZLDS); (iii) moderately urbanized zone with high development speed (MUZHDS); (iv) moderately urbanized zone with low development speed (MUZLDS); (v) lowly urbanized zone with high development speed (LUZHDS); and (vi) lowly urbanized zone with low development speed (LUZLDS). Meanwhile, spatial cluster analysis by local Moran's I was used to analyze the spatial cluster to explore the spatial inequality of urban development and identify its boundary. Buffer analysis on both sides of the boundary was carried out to reveal the development characteristics and evaluate the changes in spatial inequality.

\subsubsection{Slope Analysis}

Essentially, slope analysis calculates the slope of a linear regression equation, which is often used to study the trend of changes. In this study, slope analysis was carried out for the DN value during 2000-2012. As NTL can represent the level of urban development [25], the slope of the DN value in NTL indicates the speed of urban development. If the slope value is positive, the DN value of NTL data shows an increase trend, reflecting improvement in the level of urbanization. On the contrary, a drop in DN means the degradation in urbanization level. The higher the absolute value of the slope, the more obvious the trend of increase. Therefore, the development speed of different towns can be judged by the positive or negative slope and its absolute value. The formula is as follows:

$$
\text { Slope }=\frac{n * \sum_{i=1}^{n} i * D N_{i}-\left(\sum_{i=1}^{n} i\right)\left(\sum_{i=1}^{n} D N_{i}\right)}{n * \sum_{i=1}^{n} i^{2}-\left(\sum_{i=1}^{n} i\right)^{2}}
$$

where $n$ is the number of the years to be monitored, and $D N_{i}$ is the $\mathrm{DN}$ value of year $i$.

Since the variance of regression and off-regression is similar to the $\mathrm{F}$ distribution of $\mathrm{v} 1=1$ (v1 represents the number of variable) and $\mathrm{v} 2=n-2$ (v2 represents the degrees of freedom), the $\mathrm{F}$ test of the regression can be used to judge whether the urbanization development is significant.

\subsubsection{Spatial Cluster Analysis}

Local Moran's I can be used to test the phenomena of spatial clustering of similar or dissimilar observations in local areas. The local Moran's I of region $i$ can be used to measure the degree of the association between region $i$ and its adjacent regions. The formula is as follows:

$$
I_{i}=\frac{\left(x_{i}-\bar{x}\right)}{S_{x}^{2}} \sum_{j=1, j \neq i}^{n} W_{i j}\left(x_{j}-\bar{x}\right)
$$


where $x_{i}$ is the value of the variable $x$ at location $i ; \bar{x}$ is the average value of $x$ with the sample number of $n ; x_{j}$ is the value of the variable $x$ at all the other locations (where $j \neq i$ ); $S_{x}^{2}$ is the variance of variable $x$; and $W_{i j}$ is a weight which was based on the inverse of the distance between locations $i$ and $j$. The samples within a distance band are given the same weight, while those outside the distance band are given a weight of 0 .

In this study, Anselin local Moran's I was calculated in ArcGIS to measure the agglomeration state of areas at high development level or low development level (at 95\% confidence level). A high positive value of local Moran's I represents that a high value is surrounded by a high value (high-high), or a low value is surrounded by a low value (low-low). High-high means that the development level of the assessment area and adjacent areas are both high; while low-low shows that the development level of the assessment area and adjacent areas are both low. A high negative value of local Moran's I indicates that a low value is surrounded by a high value (low-high), or a high value is surrounded by a low value (high-low). Low-high reflects that the development level of the assessment area is low and that of its adjacent areas is high, while high-low indicates that the development level of the assessment area is high and that of its adjacent areas is low.

\section{Results}

\subsection{Development Degree}

In 2000, the development level of the Beijing-Tianjin-Hebei urban agglomeration was relatively low and demonstrated obvious spatial difference, with the mean DN value of 7.88 and the standard deviation of 12.64. The mean DN value of Beijing and Tianjin was 17.07 and 20.68 respectively, while the mean DN value of Hebei Province was only 6.27, far below the average level of Beijing and Tianjin. In addition, the standard deviation of Beijing and Tianjin reached 20.65 and 17.04 respectively, while that of Hebei Province was merely 10.39. These indicated that the development of Beijing and Tianjin was at a high level with high spatial heterogeneity, while a downturn state was widespread in Hebei Province. The development degree of towns was then divided into three levels using the method of natural break: low (mean DN value between 0 and 14.93), medium (mean DN value between 14.94 and 41.33) and high (mean DN value between 41.34 and 63). As shown in Figure 2a,b, there existed an apparent circular spatial structure in the whole region. In 2000, the high-value towns were mainly located in southern Beijing, southern Tianjin and the central urban areas of other cities like Tangshan, Shijiazhuang, and Handan. However, the area ratio of high-value towns was far less than $10 \%$ in cities, except for Beijing and Tianjin which had an area ratio of $13.74 \%$ and $11.69 \%$ respectively. The difference in area ratio not only showed the gap in the urbanization level among Beijing, Tianjin and Hebei Province, but also revealed the dispersed city size in the whole region. The medium-value towns were mainly surrounding high-value ones, lying along the edge of central urban areas and the urban-rural fringe. Low-value towns were generally located in the suburbs of Beijing, Tianjin and the vast area of Hebei Province, occupying the largest land area compared with high-value and medium-value towns. Meanwhile, there were a considerable number of towns with a mean DN value of 0 . Situated mainly in rural areas in Chengde and Zhangjiakou, the development of such towns was restricted to a low level due to their location in mountainous areas or the Bashang plateau.

Compared with 2000, the mean DN value of the whole region increased to 13.08 in 2012, presenting a great improvement. Specifically, the mean DN value of Beijing and Tianjin increased to 23.68 and 32.55 respectively, while that of Hebei Province rose to 10.93. At the same time, the standard deviation of DN value of the whole region also climbed to 17.01 in 2012, with Beijing, Tianjin and Hebei reaching $24.70,32.55$ and 14.73 respectively. These reflect a wider gap of regional development than 2000. From the perspective of spatial pattern, in 2012, the location of high-value areas and medium-value areas was basically consistent with that in 2000, with a level of expansion beyond the original external boundary. Meanwhile, the number of low-value towns gradually declined. In 2012, the high-value and medium-value areas around Beijing and Tianjin were almost spatially continuous and other 
surrounding towns were still occupied by low-value areas, creating a distinct poverty belt around Beijing and Tianjin.
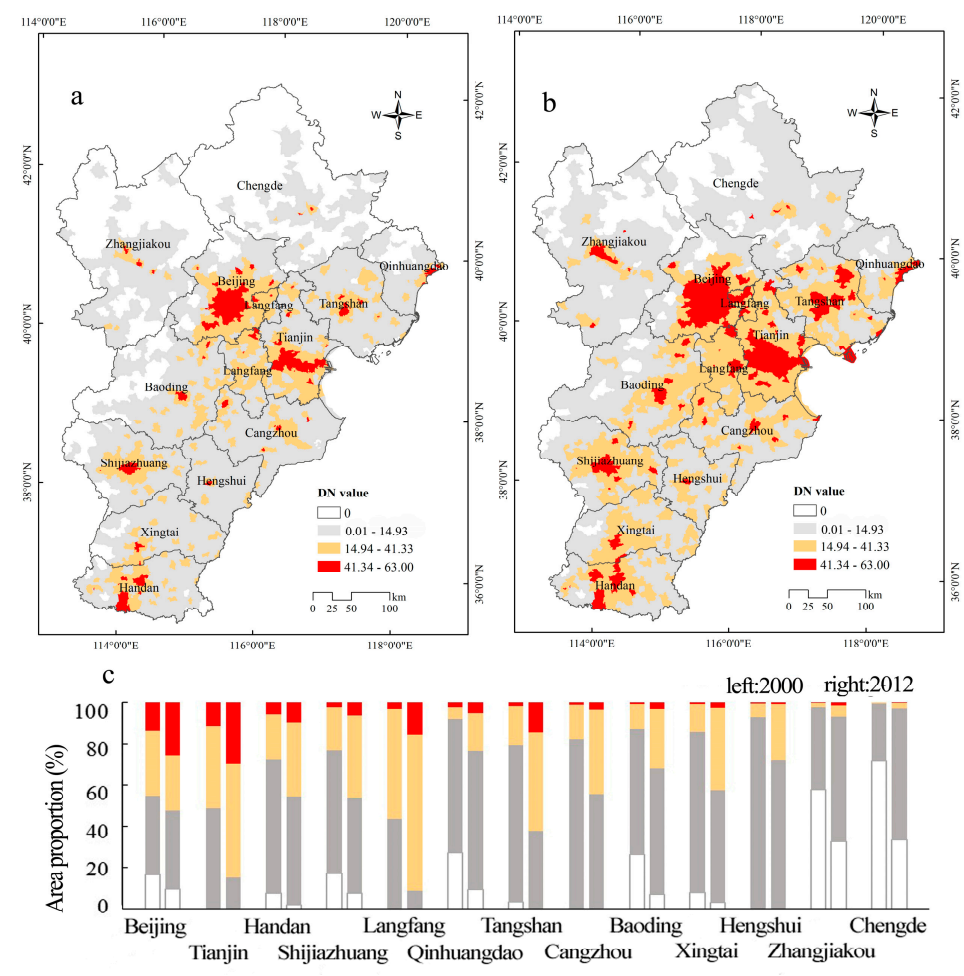

Figure 2. Spatial pattern of nighttime light in Beijing-Tianjin-Hebei urban agglomeration during 2000-2012. (a) The DN value of nighttime light image in 2000; (b) The DN value of nighttime light image in 2012; (c) Area proportion of each level in 2000 and 2012.

\subsection{Development Speed}

The changes in area ratio of each development level showed a positive correlation between the pace of development and the city size during 2000-2012 (Figure 2c). In other words, the pace of development in big cities (Beijing and Tianjin, where $20 \%$ of the total area fell within the high value class in 2012) was faster than that in medium cities (Langfang, Tangshan, Handan and Shijiazhuang, where the area ratio of high-value town was larger than 5\% and less than 20\% in 2012), and the pace of development in small cities was the slowest (where the area ratio of high-value town was lower than 5\% in 2012). During 2000-2012, big cities such as Beijing and Tianjin experienced obvious expansion in high-value areas, with an increase ratio of $11.94 \%$ and $18.31 \%$ respectively. In Langfang and Tangshan, two medium cities near Beijing and Tianjin, the high-value areas also expanded by more than $10 \%$. In the other two medium cities, Shijiazhuang and Handan, the high-value areas expanded by $3.74 \%$ and $3.85 \%$ in this period respectively. However, in small cities such as Cangzhou, the expansion of high-value area was less than 3\%, demonstrating a slow development pace. Meanwhile, it was found that in most cities, the expansion of medium-value areas was generally faster than that of high-value areas, especially in small-sized and medium-sized cities. This may on one hand be resulted from the saturation of DMSP-OLS data. On the other hand, it may be attributable to the fact that it is relatively easy for a less developed town to rise to a higher level, while an already high-level town can hardly make further progress. That is to say, there may be a threshold for cities to evolve to a high level of urbanization in the urbanization process.

In addition, the slope analysis of NTL during 2000-2012 was also carried out to evaluate the development speed of each town in the Beijing-Tianjin-Hebei urban agglomeration (Figure 3). The results showed that except for 475 towns with the slope value of 0 , the slope value of the other 
towns was all positive, indicating that the level of urbanization in the majority of towns showed an increasing trend from 2000 to 2012. Furthermore, the F test showed that out of the total 2443 towns with the development speed greater than 0, only 39 at $95 \%$ confidence level and 88 at $99 \%$ confidence level demonstrated no significant increase. Thus, the urbanization of almost all the towns could be observed clearly. From the perspective of spatial pattern, towns with a speed of 0 were mainly located in the suburbs of Chengde, Zhangjiakou and Beijing, as well as the central urban area of each city. The towns located in high-value areas were also at a low speed. On one hand, these towns had a high initial level of development, so development was relatively slow during 2000-2012, with some even close to 0 . On the other hand, it may be caused by the saturation of DMSP-OLS data. The towns located outside the high-value areas held a high development speed driven by the city center. This part of regions was generally at the forefront of urban sprawl, i.e., the potential urbanizing areas. Along the urban-rural gradient, the impact of urban radiation gradually declined with the growing distance from city center, so did development speed. In suburbs, the speed of development tended to be the lowest, and the speed of some towns was even close to 0 due to the dominance of natural ecosystems.

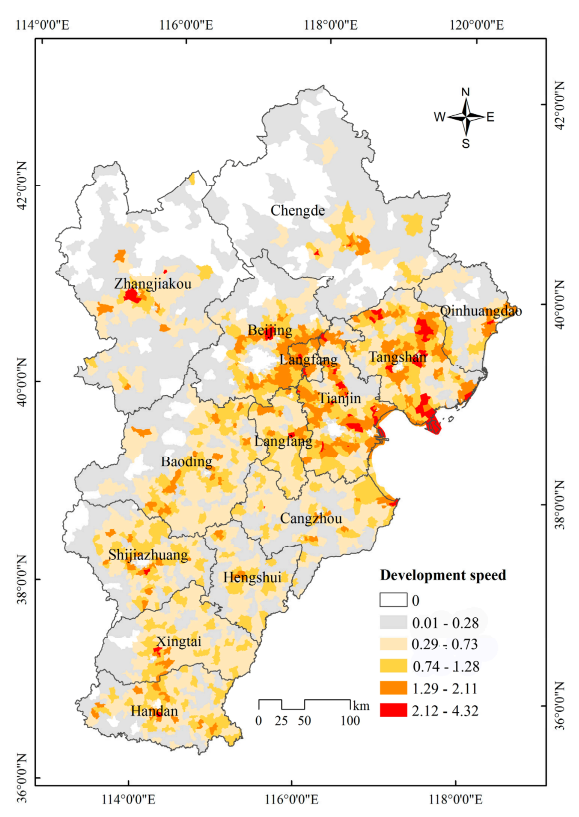

Figure 3. Spatial pattern of development speed in Beijing-Tianjin-Hebei urban agglomeration during 2000-2012.

\subsection{Spatial Pattern of Urbanization Types}

Based on the value of NTL in 2012 and the development speed during 2000-2012, towns in the Beijing-Tianjin-Hebei urban agglomeration were classified into 6 kinds of urbanization types (Figure 4). There was an obvious circular structure of HUZLDS-HUZHDS-MUZHDS-MUZLDS-LUZLDS from city center to suburb in most cities, while the distribution of LUZHDS was discrete. This circular structure in a single city is easy to understand by the spatial characteristics of development level and speed. However, the distribution of different urbanization types in the whole urban agglomeration is still worth more attention.

Comparing the distribution of urbanization types in the whole region (Table 1), it could be found that about $48.76 \%$ of HUZHDS and $57.53 \%$ of HUZLDS were distributed in Beijing and Tianjin. Affected by surrounding big cities of Beijing and Tianjin, Langfang and Tangshan were also in a relatively good development momentum. Beijing, Tianjin, Tangshan and Langfang accounted for $74.52 \%$ of HUZHDS and $63.81 \%$ of HUZLDS, creating a cluster of wealth thanks to their geographical proximity. However, located in the northwest of Beijing, Chengde and Zhangjiakou occupied $50.29 \%$ of LUZLDS, showing a large gap with the Beijing-Tianjin-Tangshan region. On one hand, the extensive 
mountainous areas and Bashang plateau restricted urban development and hindered the urban expansion from Beijing towards Chengde and Zhangjiakou. On the other hand, cities in the south and east of Beijing was closer to the Bohai Bay, supplying them with abundant resources (i.e., oil and mineral). Therefore, these cities attracted more development elements and developed to a relatively higher level. MUZHDS and MUZLDS were also mainly distributed in Beijing, Tianjin, Tangshan and Langfang, as well as some cities in southern Hebei Province. The overall urbanization pattern of the Beijing-Tianjin-Hebei urban agglomeration showed that Beijing and Tianjin was at a high degree of urbanization with rapid development, while the development of the northwestern region was lagging behind. The development of the southeastern region needed to be strengthened as well. In sum, the spatial inequality of urban development was notable in the Beijing-Tianjin-Hebei urban agglomeration.

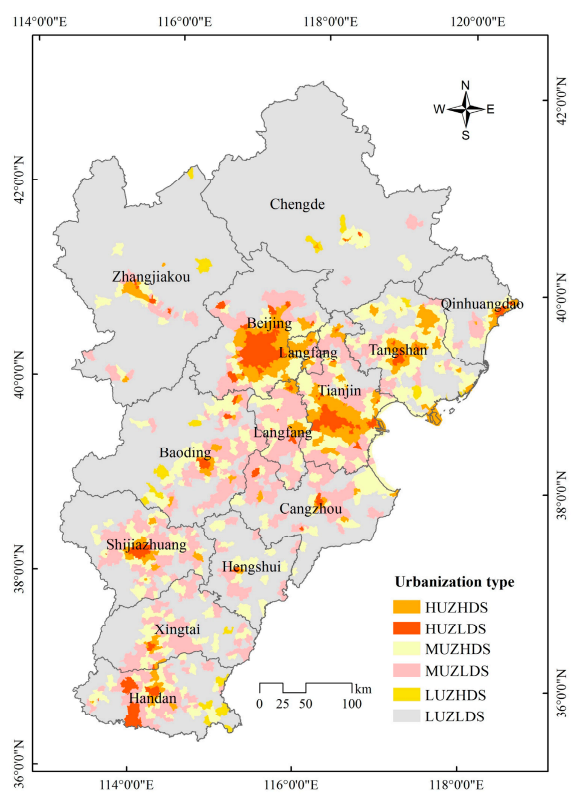

Figure 4. Spatial pattern of urbanization types in Beijing-Tianjin-Hebei urban agglomeration during 2000-2012.

Table 1. Area ratio of different cities for each urbanization type in Beijing-Tianjin-Hebei urban agglomeration (unit: \%).

\begin{tabular}{ccccccc}
\hline City & HUZHDS & HUZLDS & MUZHDS & MUZLDS & LUZHDS & LUZLDS \\
\hline Beijing & 22.89 & 38.66 & 7.50 & 8.09 & 0.00 & 5.47 \\
Tianjin & 25.87 & 18.87 & 11.73 & 10.93 & 0.00 & 1.24 \\
Handan & 3.64 & 15.79 & 7.14 & 8.45 & 27.31 & 4.26 \\
Shijiazhuang & 5.57 & 5.92 & 8.34 & 11.66 & 0.00 & 5.28 \\
Langfang & 9.09 & 2.08 & 6.27 & 10.73 & 0.00 & 0.40 \\
Qinhuangdao & 2.41 & 2.23 & 3.72 & 1.54 & 0.00 & 4.17 \\
Tangshan & 16.67 & 4.20 & 19.06 & 4.98 & 13.60 & 3.49 \\
Cangzhou & 2.78 & 3.47 & 7.71 & 12.24 & 0.00 & 5.61 \\
Baoding & 4.27 & 4.31 & 10.37 & 12.66 & 24.58 & 10.24 \\
Xingtai & 2.24 & 1.55 & 7.13 & 10.46 & 3.66 & 5.03 \\
Hengshui & 0.35 & 0.72 & 4.78 & 3.84 & 0.00 & 4.52 \\
Zhangjiakou & 3.82 & 1.74 & 3.49 & 3.51 & 16.18 & 23.67 \\
Chengde & 0.40 & 0.46 & 2.76 & 0.91 & 14.67 & 26.62 \\
\hline
\end{tabular}

\subsection{Spatial Inequality of Urban Development}

Both the increasing standard deviation and the spatial cluster of urbanization types pointed out that spatial inequality of urban development in the Beijing-Tianjin-Hebei urban agglomeration had 
become more severe. However, the study above did not identify the accurate locations of spatial inequality or the dividing boundary between the areas with high and low urbanization levels. To detect the boundary between areas with high and low development levels, local Moran's I was used to explore the spatial inequality pattern of the urban agglomeration (Figure 5). Non-significant areas of the Local Moran's I showed that there was no polarization in the region and the regional development was relatively balanced. Although spatial inequality might exist to a certain extent in this region, it was not obvious compared to the overall spatial inequality in the study area. This region accounted for about half of the total area and was mainly distributed in the southeast of the study area. The high-high type represented a high-value cluster area, where the development of the assessment area and its neighboring areas were both at a relatively higher level than other places. The places of high-high type were located in the city center of Beijing, Tianjin and some other places in Hebei Province. The low-low type occupied a large area and was mainly located along the edge of the Beijing-Tianjin-Hebei urban agglomeration. These areas and their neighboring areas were all at low development level, reflecting that local development might be at risk of stagnation as there was no external driving factor from high-level areas in the surrounding. The high-low type and low-high type are the transition zones from the high-high type to low-low type. In other words, they are the early forms of high-high type, and the future stage of low-low type. However, there were a very small number of towns belonging to the high-low and low-high types. The former was mainly located in the economic development zones in the suburb of cities, while the latter was scattered in the periphery of city centers, e.g., a large area of low-high towns existed outside the high-high towns in Zhangiiakou. Overall, the cluster pattern showed that the development of the southeast region was relatively balanced, and highly developed areas were clustered around Beijing and Tianjin. The north and west regions had a low development level.

The spatial inequality of urban development tended to intensify from 2000 to 2012 in the Beijing-Tianjin-Hebei urban agglomeration, where the area of high-high type and low-low type both increased, and the area of non-significant type declined year by year (Figure 5, Table 2). In 2000, the number of high-high towns was 635, totaling an area of $9506.02 \mathrm{~km}^{2}$. While in 2012, the number expanded to 734 , and the area reached $13,729.28 \mathrm{~km}^{2}$. The newly generated high-high areas were mainly formed by the expansion of the preexisting high-high areas, so almost no standalone new high-high patches appeared in the region. The low-low type areas increased from 446 to 675 , with a significant geographical expansion from $51,569.84 \mathrm{~km}^{2}$ to $91,779.77 \mathrm{~km}^{2}$. However, despite the increase in high-high type and low-low type areas, the area of non-significant type decreased from $139,841.33 \mathrm{~km}^{2}$ in 2000 to $95,920.83 \mathrm{~km}^{2}$ in 2012, indicating that the region with balanced development decreased. At the same time, towns of low-high type and high-low type remained a small number, suggesting that only a few towns were in the transition zone from low-low type to high-high type. With the high-high type and low-low type areas gradually increasing, the difference in development level among the towns would be enlarged. Besides, the small number of towns in the transition zone also indicated that the spatial inequality might not be significantly improved within a period of short time.

Table 2. Count and area of each type of spatial cluster towns in Beijing-Tianjin-Hebei urban agglomeration during 2000-2012.

\begin{tabular}{ccccc}
\hline & $\mathbf{2 0 0 0}$ & $\mathbf{2 0 0 4}$ & $\mathbf{2 0 0 8}$ & $\mathbf{2 0 1 2}$ \\
\cline { 2 - 5 } & Count/Area $\left.\mathbf{( k m}^{\mathbf{2}}\right)$ & Count/Area $\mathbf{( k m}^{\mathbf{2}} \mathbf{)}$ & Count/Area $\mathbf{( k m}^{\mathbf{2}} \mathbf{)}$ & Count/Area $\mathbf{( \mathbf { k m } ^ { 2 } \mathbf { ) }}$ \\
\hline High-High & $635 / 9506.02$ & $701 / 12,078.73$ & $721 / 13,087.05$ & $734 / 13,729.28$ \\
High-Low & $5 / 31.84$ & $7 / 83.41$ & $6 / 110.38$ & $8 / 144.39$ \\
Low-High & $28 / 2267.41$ & $22 / 1949.46$ & $18 / 1891.31$ & $16 / 1642.17$ \\
Low-Low & $446 / 51,569.84$ & $632 / 79789.54$ & $653 / 87,104.92$ & $675 / 91,779.77$ \\
Non-significant & $1804 / 139,841.33$ & $1556 / 109,315.30$ & $1520 / 101,022.78$ & $1485 / 95,920.83$ \\
\hline
\end{tabular}



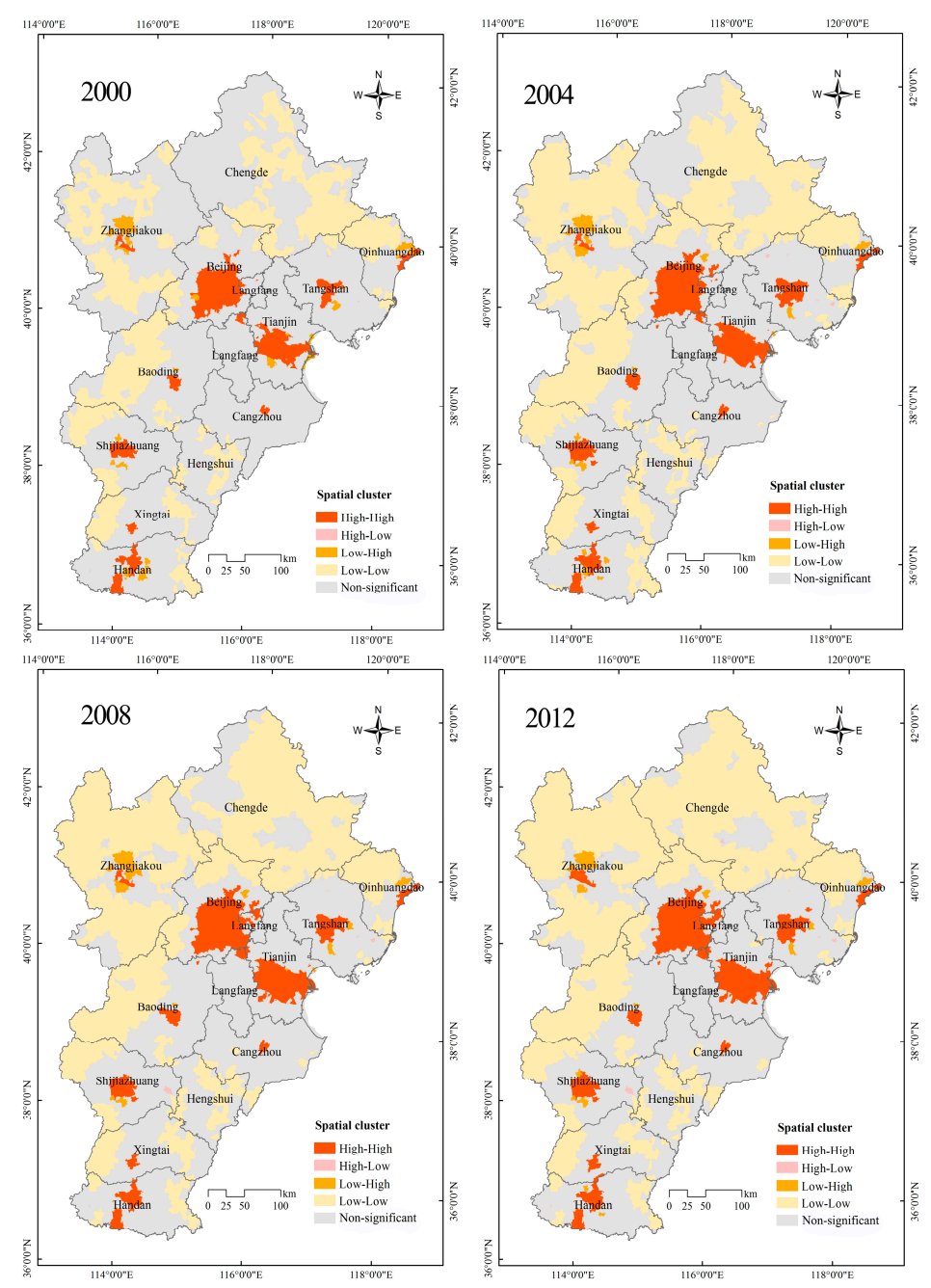

Figure 5. Spatial cluster of urban development in Beijing-Tianjin-Hebei urban agglomeration during 2000-2012.

\section{Discussion}

\subsection{Trends of Change in Spatial Inequality}

As discussed above, the development gap between Beijing-Tianjin and Hebei Province was widened, and the spatial inequality between them was the most notable in the Beijing-Tianjin-Hebei urban agglomeration. Therefore, it was of great importance to identify the boundary of spatial inequality around Beijing and Tianjin. By comparing the development rate of both sides of the boundary, we can judge whether the gap of development level would be widened, and the evolution trend of spatial inequality can thus be explored. The inequality boundary is defined as the transition line of two different development levels, which is a relatively dynamic line in the urbanization process. In this study, the boundary of high-high type towns in Beijing and Tianjin was treated as the inequality boundary due to the development gap between both sides. Specifically, as high-high type areas were all at a high development level and its neighboring areas at a low development level, there was a sudden change in development level on both sides of the boundary of high-high type in the Beijing-Tianjin-Hebei urban agglomeration.

Buffers were made every $5 \mathrm{~km}$ to analyze the difference in development characteristics inside and outside the inequality boundary. For a dynamic analysis, the spatial inequality in four years $-2000,2004,2008,2012$ - was explored by comparing the mean DN value in each year for each buffer 
(Figure 6) and calculating the development speed of each buffer inside and outside the inequality boundary during 2000-2012 (Figure 7). As shown in Figure 6, although the mean DN value of each buffer increased from 2000 to 2012, the overall trend was consistent in the urban-rural gradient. At the buffer with the distance of $-30 \mathrm{~km}$ (city center), the mean DN value stood at around 63 as these areas were at a constantly high development level. With the distance changing from $-20 \mathrm{~km}$ to 0 (the location of inequality boundary), the mean DN value showed a dramatic decrease, and the decrease continued to $10 \mathrm{~km}$ outside the inequality boundary. The decrease here revealed that the spatial inequality of urban development between urban area and rural area was extremely severe in Beijing and Tianjin. When the distance changed from $10 \mathrm{~km}$ to $150 \mathrm{~km}$, the mean value of DN showed a slow downward trend, eventually reaching a stably low level outside $150 \mathrm{~km}$. This part of regions was at a low development level as the driving effect of urban areas declined with the growing distance from Beijing and Tianjin. As a whole, there was no obvious improvement in the spatial inequality of urban development between Beijing-Tianjin and Hebei from 2000 to 2012, and the spatial inequality between urban and rural areas was also relatively serious in Beijing and Tianjin.

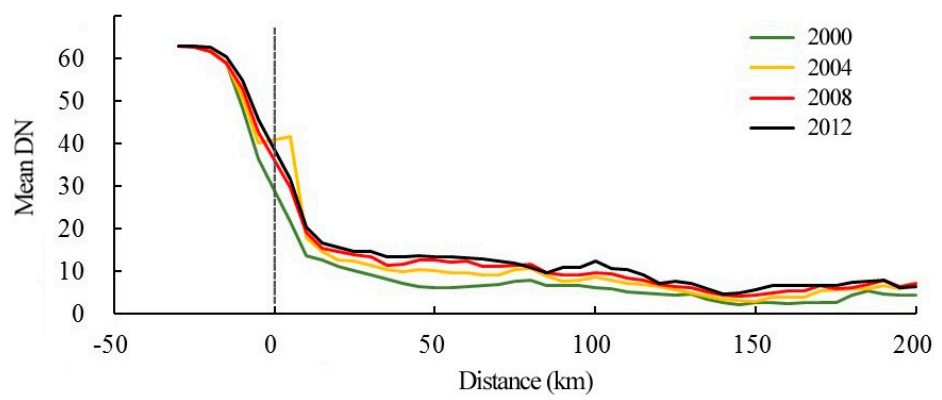

Figure 6. Changes of urban development inside and outside the inequality boundary in Beijing-Tianjin-Hebei urban agglomeration during 2000-2012.

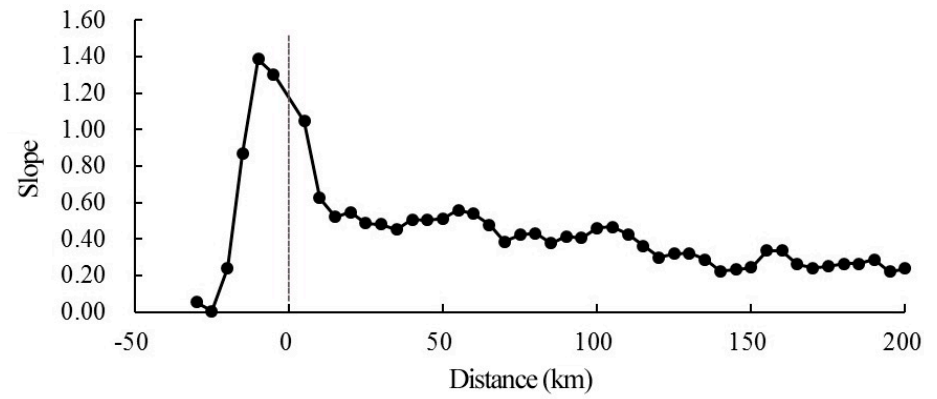

Figure 7. Speed of change in urban development inside and outside the inequality boundary in Beijing-Tianjin-Hebei urban agglomeration during 2000-2012.

From the perspective of development speed during 2000-2012, almost all the buffers achieved an increase except for those in city center. Specifically, the speed of the buffers in city center tended to be 0 due to its consistently high level in the study period. The development speed showed a gradual upward trend from city center $(-25 \mathrm{~km})$ to $10 \mathrm{~km}$ inside the inequality boundary. Theoretically, regions closer to the city center could own a faster development speed due to the proximity to urban areas. However, these regions were already at a relatively high development level at the initial stage with a high DN value, and the increase of their DN value was limited by light saturation. Therefore, the development of regions closer to city center presented a slower speed than areas outward in a certain range. The speed reached the maximum at $-10 \mathrm{~km}$, and then followed by a rapid decline outward to $15 \mathrm{~km}$ outside the inequality boundary. Beyond $15 \mathrm{~km}$, the regional development speed started to decline slowly with some fluctuations. In brief, the development speed inside inequality boundary 
was higher than that outside the boundary. Therefore, the gap would be enlarged between urban and rural areas in Beijing and Tianjin, and between Beijing-Tianjin and Hebei Province. Predictably, the spatial inequality will intensify and can hardly be improved in a short period.

The spatial inequality of urban development also revealed the structure of dispersion in city size in the Beijing-Tianjin-Hebei urban agglomeration. As the leading cities in the region, Beijing and Tianjin had great siphon effect on monetary capital, human resources and other development elements, accelerating their own urbanization process. However, the leading cities performed unsatisfactorily in driving and promoting the development of other cities in Hebei Province. Hebei Province was mainly occupied by small-sized and medium-sized cities, lacking large-sized ones to fuel development. The dispersion structure of city size made it difficult to form an organic whole for mutual cooperation and joint development. Although there was a certain synergistic effect between Beijing and Tianjin, there was also intense resource plunder and interregional competition due to their spatial proximity. As a consequence, spatial inequality of urban development spread in the Beijing-Tianjin-Hebei urban agglomeration. In case this trend continued, the development of the whole region could be restricted and become unsustainable, worsening the life quality of local residents. Fortunately, Beijing and Tianjin have tried to transfer industrial areas towards other cities in Hebei province, potentially gearing up their development and reducing future urban disparities. The Xiong'an New Area has also been set up in Hebei Province to receive and develop a portion of economic activities from Beijing. As it is expected to be a new growth pole in Hebei Province, it has the potential to help adjust and optimize the urbanization pattern of the whole region through the attraction and reallocation of development resources.

\subsection{Limitations and Future Prospects}

In this study, using DMSP/OLS nighttime light image, urbanization types of each town in the Beijing-Tianjin-Hebei urban agglomeration was categorized based on development level and speed. Meanwhile, the spatial inequality of urban development was analyzed by local Moran's I and the evolution trend of spatial inequality was explored. Nonetheless, the study was confined by various factors.

Despite the great advantages of DMSP/OLS in urbanization-related studies, there are still limitations in the representativeness of urbanization level based on DMSP/OLS nighttime light data. Firstly, the characterization of urbanization is limited by the saturation of NTL data, since the $\mathrm{DN}$ value is limited to the range of 0 to 63 [35]. At the early stage of urbanization, DN value in NTL image is effective in expressing the development level in the region. However, it is difficult to reflect the further development in a highly-developed city through the change in DN value. Meanwhile, although previous studies have justified a strong correlation between NTL and GDP, and between NTL and population [36-38], the same DN value might correspond to different GDP and population in different regions. Therefore, NTL can only describe the level of development to a certain extent, and may not be an accurate representation of the overall situation. In addition, DMSP/OLS nighttime light data has a strong spillover effect. That is to say, dark areas may be lighted brighter by surrounding areas, making it difficult to objectively reflect the differences of regional development. The Nighttime Visible Infrared Imaging Radiometer Suite (VIIRS) Day/Night Band (DNB) nighttime light, put into use in 2013, may solve the saturation and spillover effects to some degree, as the resolution of its sensor is better than the DMSP/OLS $[39,40]$. Last but not least, population, GDP, NDVI and other indicators should be applied to improve the NTL data to make it more adaptive in further studies [41].

\section{Conclusions}

Development pattern has substantial influence on the overall development of urban agglomerations. In this study, based on NTL data, the characteristics of internal development pattern was explored in the Beijing-Tianjin-Hebei urban agglomeration. Spatial inequality of urban development was revealed by the spatial analysis of urbanization types and characteristics of clusters. 
It was also shown that the spatial inequality would be enlarged. This study aimed to apply the NTL data to study the development mechanism in urban agglomeration and successfully revealed the spatial inequality and its internal characteristics in the Beijing-Tianjin-Hebei region. It is of great importance to address the regional inequality and accelerate the process of regional integration to ensure the sustainability of the urban agglomeration.

Acknowledgments: This research is financially supported by grants from the National Natural Science Foundation of China (No. 41330747).

Author Contributions: Yi'na Hu, Jian Peng and Yanxu Liu conceived and designed the study; Yi'na Hu and Yanxu Liu made substantial contributions to acquisition, analysis, and interpretation of the data; Yi'na Hu and Jian Peng wrote the first draft of the article. Yanxu Liu, Yueyue Du, Huilei Li and Jiansheng Wu reviewed and edited the first draft. All authors read and approved the submitted manuscript, agreed to be listed, and accepted the version for publication.

Conflicts of Interest: The authors declare no conflict of interest.

\section{References}

1. Li, J.; Song, C.; Cao, L.; Zhu, F.; Meng, X.; Wu, J. Impacts of landscape structure on surface urban heat islands: A case study of Shanghai, China. Remote Sens. Environ. 2011, 115, 3249-3263. [CrossRef]

2. Alnsour, J. Managing urban growth in the city of Amman, Jordan. Cities 2016, 50, 93-99. [CrossRef]

3. Liu, Z.; He, C.; Zhou, Y.; Wu, J. How much of the world's land has been urbanized, really? A hierarchical framework for avoiding confusion. Landsc. Ecol. 2014, 29, 763-771. [CrossRef]

4. Lu, D.; Hetrick, S.; Moran, E.; Li, G. Detection of urban expansion in an urban-rural landscape with multitemporal QuickBird images. J. Appl. Remote Sens. 2010, 4, 201-210. [CrossRef] [PubMed]

5. Fang, C.; Yu, D. Urban agglomeration: An evolving concept of an emerging phenomenon. Landsc. Urban Plan. 2017, 162, 126-136. [CrossRef]

6. Graham, D.; Melo, P.; Levinson, D. Agglomeration, accessibility, and productivity: Evidence for urbanized areas in the US. Work. Pap. 2012, 441, 229-232.

7. Lo, C. Urban indicators of China from radiance-calibrated digital DMSP-OLS nighttime images. Ann. Assoc. Am. Geogr. 2002, 92, 225-240. [CrossRef]

8. Yu, B.; Shu, S.; Liu, H.; Song, W.; Wu, J.; Wang, L.; Chen, Z. Object-based spatial cluster analysis of urban landscape pattern using nighttime light satellite images: A case study of China. Int. J. Geogr. Inf. Sci. 2014, 28, 2328-2355. [CrossRef]

9. Folmer, H.; Oosterhaven, J. Spatial Inequalities and Regional Development; Springer Netherland: Dordrecht, The Netherlands, 1979.

10. Wei, Y. Spatiality of regional inequality. Appl. Geogr. 2015, 61, 1-10. [CrossRef]

11. Kanbur, R.; Venables, T. Introduction: Spatial inequality and development. J. Econ. Geogr. 2005, 5, 1-2. [CrossRef]

12. Li, L.; Stough, R.R. Development of metropolitan areas-Theoretical evolution. In International Experiences and Chinese Characteristics; Science Press: Beijing, China, 2007.

13. Gottmann, J. Megalopolis: The Urbanized Northeastern Seaboard of the United State; Sciences Po University Press: Paris, France, 1961.

14. Gottmann, J. Megalopolis or the Urbanization of the Northeastern Seaboard. Econ. Geogr. 1957, 33, 189-200. [CrossRef]

15. Baigent, E.; Patrick, G.; Lewis, M.; Jean, G. Divisions over 'Megalopolis'. Prog. Hum. Geogr. 2004, 28, 687-700. [CrossRef]

16. Fragkias, M.; Seto, K. Evolving rank-size distributions of intra-metropolitan urban clusters in south china. Comput. Environ. Urban 2009, 33, 189-199. [CrossRef]

17. Li, J.; Li, C.; Zhu, F.; Song, C.; Wu, J. Spatiotemporal pattern of urbanization in shanghai, China between 1989 and 2005. Landsc. Ecol. 2013, 28, 1545-1565. [CrossRef]

18. Peng, J.; Ma, J.; Yuan, Y.; Wei, H.; Pang, W. Integrated urban land-use zoning and associated spatial development: Case study in Shenzhen, China. J. Urban Plan. Dev. 2014, 141, 05014025. [CrossRef]

19. Peng, J.; Zhao, S.; Liu, Y.; Tian, L. Identifying the urban-rural fringe using wavelet transform and kernel density estimation: A case study in Beijing city, China. Environ. Model. Softw. 2016, 83, 286-302. [CrossRef] 
20. Imhoff, M.; Lawrence, W.; Stutzer, D.; Elvidge, C. A technique for using composite DMSP/OLS "city lights" satellite data to map urban area. Remote Sens. Environ. 1997, 61, 361-370. [CrossRef]

21. Zhou, Y.; Smith, S.; Zhao, K.; Imhoff, M.; Thomson, A.; Bond, B.; Asrar, G.; Zhang, X.; He, C.; Elvidge, C. A global map of urban extent from nightlights. Environ. Res. Lett. 2015, 10, 054011. [CrossRef]

22. Lu, D.; Tian, H.; Zhou, G.; Ge, H. Regional mapping of human settlements in southeastern China with multisensor remotely sensed data. Remote Sens. Environ. 2008, 112, 3668-3679. [CrossRef]

23. Zhang, Q.; Seto, K. Can night-time light data identify typologies of urbanization? A global assessment of successes and failures. Remote Sens. 2013, 5, 3476-3494. [CrossRef]

24. Zhang, Z.; Su, S.; Xiao, R.; Jiang, D.; Wu, J. Identifying determinants of urban growth from a multi-scale perspective: A case study of the urban agglomeration around Hangzhou bay, China. Appl. Geogr. 2013, 45, 193-202. [CrossRef]

25. Yi, K.; Tani, H.; Li, Q.; Zhang, J.; Guo, M.; Bao, Y.; Wang, X.; Li, J. Mapping and evaluating the urbanization process in northeast China using DMSP/OLS nighttime light data. Sensors 2014, 14, 3207-3226. [CrossRef] [PubMed]

26. Yu, T. Structure and restructuring of Beijing-Tianjin-Hebei Megalopolis in China. Chin. Geogr. Sci. 2006, 16, 1-8. [CrossRef]

27. Zhang, Z.; Li, N.; Wang, X.; Liu, F.; Yang, L. A comparative study of urban expansion in Beijing, Tianjin and Tangshan from the 1970s to 2013. Remote Sens. 2016, 8, 496. [CrossRef]

28. Wu, W.; Zhao, S.; Zhu, C.; Jiang, J. A comparative study of urban expansion in Beijing, Tianjin and Shijiazhuang over the past three decades. Landsc. Urban Plan. 2015, 134, 93-106. [CrossRef]

29. He, C.; Liu, Z.; Tian, J.; Ma, Q. Urban expansion dynamics and natural habitat loss in China: A multiscale landscape perspective. Glob. Chang. Biol. 2014, 20, 2886-2902. [CrossRef] [PubMed]

30. Ma, X.; Tong, X.; Liu, S.; Luo, X.; Xie, H.; Li, C. Optimized sample selection in SVM classification by combining with DMSP-OLS, Landsat NDVI and GlobeLand30 Products for extracting urban built-up areas. Remote Sens. 2017, 9, 236. [CrossRef]

31. NOAA. National Centers for Environmental Information. Available online: http://ngdc.noaa.gov/eog/ dmsp/downloadV4composites.html (accessed on 10 December 2013).

32. Zhou, Y.; Smith, S.; Elvidge, C.; Zhao, K.; Thomson, A.; Imhoff, M. A cluster-based method to map urban area from DMSP/OLS nightlights. Remote Sens. Environ. 2014, 147, 173-185. [CrossRef]

33. Liu, Z.; He, C.; Zhang, Q.; Huang, Q.; Yang, Y. Extracting the dynamics of urban expansion in China using DMSP-OLS nighttime light data from 1992 to 2008. Landsc. Urban Plan. 2012, 106, 62-72. [CrossRef]

34. Gao, B.; Huang, Q.; He, C.; Ma, Q. Dynamics of urbanization levels in China from 1992 to 2012: Perspective from DMSP/OLS nighttime light data. Remote Sens. 2015, 7, 1721-1735. [CrossRef]

35. Zhang, Q.; Schaaf, C.; Seto, K.C. The vegetation adjusted NTL urban index: A new approach to reduce saturation and increase variation in nighttime luminosity. Remote Sens. Environ. 2013, 129, 32-41. [CrossRef]

36. Amaral, S.; Monteiro, A.; Camara, G.; Quintanilha, J. DMSP/OLS night-time light imagery for urban population estimates in the Brazilian Amazon. Int. J. Remote Sens. 2006, 27, 855-870. [CrossRef]

37. Ghosh, T.; Anderson, S.; Powell, R.L.; Sutton, P.; Elvidge, C. Estimation of Mexico's informal economy and remittances using nighttime imagery. Remote Sens. 2009, 1, 418-444. [CrossRef]

38. Chen, X.; Nordhaus, W. Using luminosity data as a proxy for economic statistics. Proc. Natl. Acad. Sci. USA 2011, 108, 8589-8594. [CrossRef]

39. Yu, B.; Shi, K.; Hu, Y.; Huang, C.; Chen, Z.; Wu, J. Poverty evaluation using NPP-VIIRS nighttime light composite data at the county level in China. IEEE J. STARS 2015, 8, 1217-1229. [CrossRef]

40. Dou, Y.; Liu, Z.; He, C.; Yue, H. Urban land extraction using VIIRS nighttime light data: An evaluation of three popular methods. Remote Sens. 2017, 9, 175. [CrossRef]

41. He, C.; Ma, Q.; Liu, Z.; Zhang, Q. Modeling the spatiotemporal dynamics of electric power consumption in mainland China using saturation-corrected DMSP/OLS nighttime stable light data. Int. J. Digit. Earth 2014, 7, 993-1014. [CrossRef]

(C) 2017 by the authors. Licensee MDPI, Basel, Switzerland. This article is an open access article distributed under the terms and conditions of the Creative Commons Attribution (CC BY) license (http:/ / creativecommons.org/licenses/by/4.0/). 